\title{
Anatomical Variations in Branching Pattern of Arch of Aorta - A Cadaveric Study in South Indian Population
}

\author{
S Kantharaj Naik ${ }^{\circledR 1}$, S.A. Premchand ${ }^{\circledR 1}$, W Benjamin ${ }^{\circledR 2}$ \\ ${ }^{1}$ Assistant Professor, Department of Anatomy, JJM Medical College, Davangere, Karnataka, India, ${ }^{2}$ Assistant Professor, Department of Anatomy, P K Das Institute of \\ Medical Sciences, Vaniamkulam, Ottapalam, Palakkad, Kerala, India.
}

\section{Abstract}

Background: Knowledge of the branching pattern of arch of aorta is important in avoiding surgical and accidental injuries during aortic instrumentation, thoracic and neck surgeries. Subjects and Methods: The present study is based on dissections that were performed on 50 properly embalmed human cadaver specimens. The anatomical variations of arch of aorta and its branches, diameter of its branches at site of origin and distance of each branch from the point of origin to median plane were measured. Results: The usual three branched pattern of arch of aorta was found in 36 specimens (72\%). The common trunk for both brachiocephalic trunk and left common carotid artery was present in 10 specimens (20\%). In 2 specimens (4\%), the arch gives four branches, left vertebral artery being additional branch. In 1 specimen ( $2 \%)$, the arch gives three branches namely; common trunk for brachiocephalic trunk and left common carotid artery, left vertebral artery and left subclavian artery. In 1 specimen (2\%), the arch gives three branches namely; brachiocephalic trunk, left common carotid artery and common trunk for left vertebral artery and left subclavian artery. Conclusion: The results in this study provide significant information vital for anatomists, cardiovascular surgeons and radiologists.

Keywords: Arch of Aorta, Common Trunk, Brachiocephalic Trunk, Left Common Carotid Artery, Left Subclavian Artery, Left Vertebral Artery

Corresponding Author: S.A. Premchand, Assistant Professor, Department of Anatomy, JJM Medical College, Davangere, Karnataka, India.

E-mail: premchandsa@gmail.com

Received: 30 September 2020

Revised: 15 November 2020

Accepted: 24 November 2020

Published: 22 December 2020

\section{Introduction}

The aorta is the main arterial trunk of systemic circulation. For descriptive purposes it is divided into the ascending aorta, the arch of aorta, and the descending aorta, the last being further divided into thoracic and abdominal parts. Three branches usually arise from the arch's convex superior aspect, the brachiocephaic trunk (BCT), left common carotid (LCCA) and left subclavian (LSA) arteries. ${ }^{[1]}$

Study of the branching pattern of arch of aorta is of considerable significance, due to repeated intervention by intervention cardiologists and cardiothoracic surgeons. ${ }^{[2]}$ The arch of aorta is also an important site of endovascular repair. ${ }^{[2,3]}$ The anomalous origins and distribution of the large branches of the arch can result in change in the cerebral hemodynamics that might lead to cerebrovascular catastrophes. ${ }^{[4]}$ The aim of present study was to observe the branching pattern of arch of aorta, incidence of its variations and its clinical significance.

\section{Subjects and Methods}

Fifty properly embalmed human cadaver specimens (40 adult cadavers and 10 still born fetuses) belonging to south Indian origin were dissected to expose structures in superior mediastinum. The arch of aorta was dissected with proper care to identify its branches namely; brachiocephalic trunk, left common carotid artery and left subclavian artery.

Variations in the branching pattern, diameter of its branches at site of origin and distance of each branch from the point of origin to median plane were measured. Morphological parameters were recorded using digital vernier caliper and photographs were clicked with digital camera. The statistical analysis of collected data was done using the SPSS program.

Results

Anatomical variations in branching pattern of arch of aorta [Chart 1] 


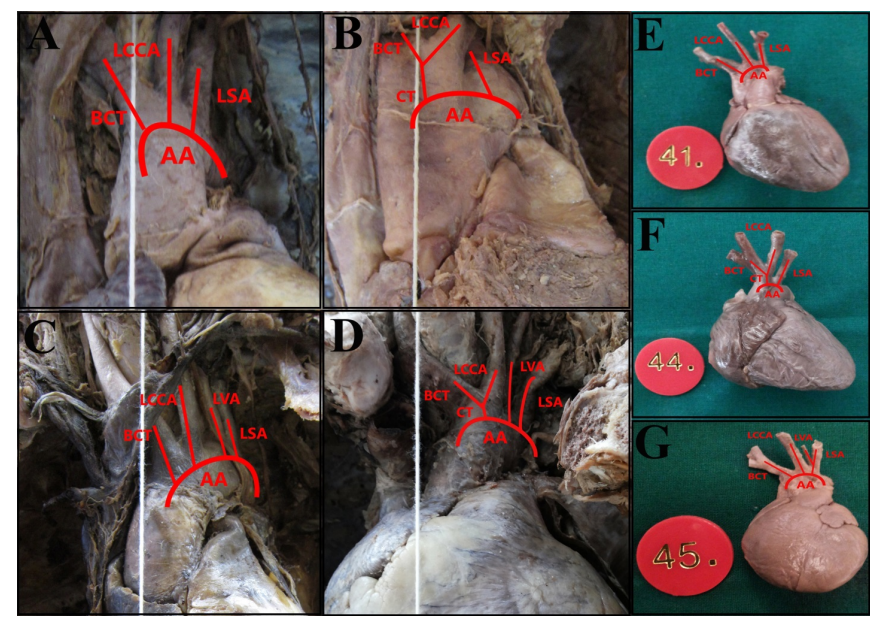

Figure 1: Photographs showing variations in branching pattern of the arch of aorta. A: Usual pattern of 3 major branches arising from the arch. B: 2 branches arising from arch with common trunk for BCT and LCCA. C: 4 branches arising from the arch, LVA being additional branch between LCCA and LSA. D: 3 branches arising from arch with common trunk for BCT and LCCA and origin of LVA from arch. E: Fetal specimen with usual pattern of 3 major branches arising from the arch. $F$ : Fetal specimen with 2 branches arising directly from arch; a common trunk for BCT and LCCA, LSA as second branch. G: Fetal specimen with 3 branches arising directly from arch; BCT, LCCA and a common trunk for LVA and LSA.

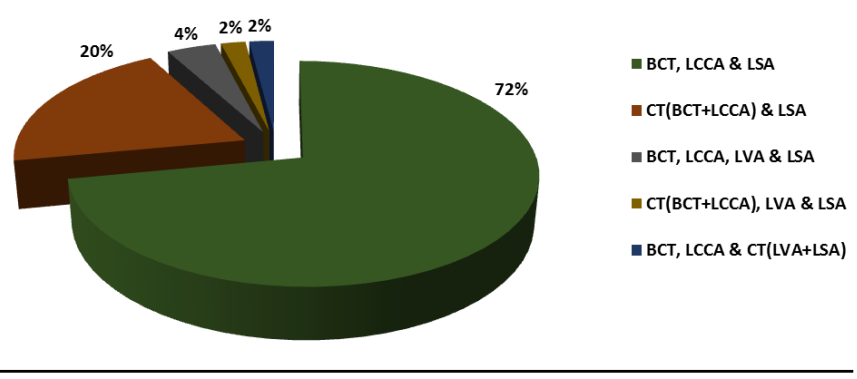

Chart 1: Variations in the branching pattern of Arch of Arota

The usual pattern of three major branches; BCT, LCCA and LSA arising independently from the arch were observed in 36 cadavers $(72 \%)$ [Figure 1A, 1E]. Four types of variations were observed in 14 cadavers $(28 \%)$, either in the form of increase or decrease in number of branches arising from the arch and common origin of two branches.
In 10 cadavers $(20 \%)$, the arch had two branches namely; a common trunk for BCT and LCCA with LSA as second branch [Figure $1 \mathrm{~B}, 1 \mathrm{~F}$ ]. In 2 cadavers $(4 \%)$, four branches originated independently from the arch namely; BCT, LCCA, LVA and LSA [Figure 1C]. In 1 cadaver (2\%), the arch had three branches namely; common trunk for BCT and LCCA with LVA and LSA as second and third branch respectively [Figure 1D]. In 1 cadaver $(2 \%)$, the arch had three branches namely; BCT, LCCA and a common trunk for LVA and LSA as third branch [Figure $1 \mathrm{G}$ ].

\section{Distance from the median plane to the origin of the branches of arch of aorta [Table 1]}

The distance from the median plane to the origin of BCT was an average of $3.88 \pm 1.58 \mathrm{~mm}$ to the left and $3.41 \pm 1.00$ $\mathrm{mm}$ to the right. The distance from the median plane to the origin of LCCA was an average of $13.44 \pm 3.13 \mathrm{~mm}$ to the left. The distance from the median plane to the origin of LSA was an average of $24.29 \pm 3.39 \mathrm{~mm}$ to the left. The distance from the median plane to the origin of CT (BCT $+\mathrm{LCCA})$ was an average of $6.25 \pm 5.64 \mathrm{~mm}$ to the left and $3.80 \pm 1.27 \mathrm{~mm}$ to the right. The distance from the median plane to the origin of LVA was an average of $21.22 \pm 6.78 \mathrm{~mm}$ to the left.

\section{Diameter of branches of the arch of aorta at site of origin [Table 2]}

The mean diameter of BCT was $13.57 \pm 1.59 \mathrm{~mm}$. The mean diameter of LCCA was $8.27 \pm 0.89 \mathrm{~mm}$. The mean diameter of LSA was $11.46 \pm 1.20 \mathrm{~mm}$. The mean diameter of CT (BCT+LCCA) was $21.59 \pm 1.98 \mathrm{~mm}$. The mean diameter of LVA was $4.54 \pm 1.02 \mathrm{~mm}$.

\section{Discussion}

Among the most important concerns in the study of the vascular system are its major variations. Although many of them do not cause disturbance in the functions of the body, they may be of great importance to the surgeon. Many of the variations are due to different modes of change of the primary vessels of the branchial arches, during embryonic period of gestation. ${ }^{[5-7]}$

An analysis of variation in branches from 1000 aortic arches by Anson in 1963, showed 65\% with usual pattern; in 27\% left common carotid and the brachiocephalic trunk had a common trunk; in $2.5 \%$ the four arteries branched separately from the arch. The remaining $5 \%$ showed a great variety of patterns. ${ }^{[1]}$ In present study usual branching pattern was seen in $72 \%$, with $28 \%$ variant branching pattern. This finding was nearly comparable to that of Alsaif HA and Ramdan WS, Gupta and Sodhi where $70 \%$ had usual branching pattern. ${ }^{[10,15]}$ Various studies have documented different frequencies of this variation in different population [Table 3]. 


\begin{tabular}{|c|c|c|c|c|c|c|c|}
\hline Branches & $\mathbf{N}$ & $\begin{array}{l}\text { Side of devia- } \\
\text { tion }\end{array}$ & Mean & SD & Minimum & Maximum & Range \\
\hline \multirow[t]{2}{*}{$\mathrm{BCT}$} & 22 & Left & 3.88 & \pm 1.58 & 2.10 & 7.98 & 5.88 \\
\hline & 7 & Right & 3.41 & \pm 1.00 & 1.72 & 4.74 & 3.02 \\
\hline LCCA & 30 & Left & 13.44 & \pm 3.13 & 8.02 & 18.62 & 10.60 \\
\hline LSA & 38 & Left & 24.29 & \pm 3.39 & 18.26 & 32.34 & 14.08 \\
\hline \multirow[t]{2}{*}{$\mathrm{CT}(\mathrm{BCT}+\mathrm{LCCA})$} & 5 & Left & 6.25 & \pm 5.64 & 1.64 & 12.48 & 10.84 \\
\hline & 3 & Right & 3.80 & \pm 1.27 & 2.98 & 5.26 & 2.28 \\
\hline LVA & 3 & Left & 21.22 & \pm 6.78 & 13.52 & 26.32 & 12.80 \\
\hline
\end{tabular}

Table 2: Diameter of its branches at site of origin.

\begin{tabular}{lllllll}
\hline Branches & N & Mean & SD & Minimum & Maximum & Range \\
BCT & 40 & 13.57 & \pm 1.59 & 9.26 & 16.52 & 7.26 \\
LCCA & 40 & 8.27 & \pm 0.89 & 6.16 & 10.03 & 3.87 \\
LSA & 40 & 11.46 & \pm 1.20 & 8.46 & 14.13 & 5.67 \\
CT $($ BCT+LCCA) & 9 & 21.59 & \pm 1.98 & 18.38 & 24.88 & 6.50 \\
LVA & 3 & 4.54 & \pm 1.02 & 3.68 & 5.66 & 1.98 \\
\hline
\end{tabular}

The present study on South Indian population may provide acceptable information on branching pattern of arch of aorta and morphometric data about the branches for safely performing endovascular surgery. These variations have to be taken into concern by surgeons when they are planning surgical or diagnostic interventions involving arch of aorta and its branches. Surgeons must be conscious of possible variations of the major arteries and be able to identify them. Correct identification of these vessels is very important for suitable invasive techniques in order to achieve desired objectives and to avoid major complications especially during vascular surgery. The anatomic and morphologic variations of the arch of aorta and its branches are significant for diagnostic and surgical procedures in the thorax and neck. ${ }^{[6,7]}$

\section{Conclusion}

The present study on South Indian population provides considerable information on the branching pattern of arch of aorta. The variation in branching pattern of arch of aorta was at par with the studies in other population of the world. The various variation of this study should be considered during aortic angiography, aortic instrumentation, supraaortic thoracic surgeries and head and neck surgeries.

\section{References}

1. Peter L, Williams LH, Bannister MM, Berry P, Collins M, Dyson JE, et al. Gray's anatomy: the anatomical basis of medicine and surgery. London: Churchill Livingstone; 1995.
2. Shin IY, Chung YG, Shin WH, Im SB, Hwang SC, Kim BT. A Morphometric Study on Cadaveric Aortic Arch and Its Major Branches in 25 Korean Adults : The Perspective of Endovascular Surgery. J Korean Neurosurg Soc. 2008;44(2):78. Available from: https://dx.doi.org/10.3340/jkns.2008.44.2.78.

3. Suzuki K, Kazui T, Bashar AHM, Yamashita K, Terada H, Washiyama N, et al. Total Aortic Arch Replacement in Patients With Arch Vessel Anomalies. Ann Thorac Surg. 2006;81(6):2079-2083. Available from: https://dx.doi.org/10. 1016/j.athoracsur.2005.12.062.

4. Bernardi L, Dettori P. Angiographic study of a rare anomalous origin of the vertebral artery. Neuroradiol. 1975;9(1):43-47. Available from: https://dx.doi.org/10.1007/bf00330136.

5. Bergman RA, Thompson SA, Afifi AK, Saodeh FA. Compendum of human anatomic variation. Gemany: Urban and Schwarzenberg; 1988.

6. Fazan VPS, Ribeiro RA, Ribeiro JAS, Filho OAR. Right retroesophageal subclavian artery. Acta Cir Bras. 2003;18(suppl 5):54-56. Available from: https://dx.doi.org/10.1590/s010286502003001200020 .

7. Anson BV, Mcvay CB. Thoracic cavity and its contents. In: BV A, CB M, editors. Surgical anatomy. 5th ed. Philadelphia: WB; 1971. p. 370-460.

8. Adachi B. Das arterial system der Japaner. Tokyo: Ken Kyushu Publishing Co; 1928.

9. Nelson ML, Sparks CD. Unusual aortic arch variation: Distal origin of common carotid arteries. Clin Anat. 2001;14(1):62-65. Available from: https://dx.doi.org/10.1002/ 1098-2353(200101)14:1<62::aid-ca1012>3.0.co;2-\#.

10. Gupta M, Sodhi L. Variations in the branching pattern, shape of arch of aorta. J Anat Soc of India. 2003;52(1):82-85.

11. Nayak SR, Pai MM, Prabhu LV, D'Costa S, Shetty P. Anatomical organization of aortic arch variations in the India: 
Table 3: Incidence of variant branching pattern of arch of aorta in different populations.

\begin{tabular}{|c|c|c|c|c|c|c|c|}
\hline \multirow[t]{2}{*}{ Study } & \multirow[t]{2}{*}{ Year } & \multirow[t]{2}{*}{ Population } & \multirow[t]{2}{*}{$\%$ of usual } & \multirow[t]{2}{*}{$\%$ of } & \multicolumn{3}{|c|}{ Types of variation in \% } \\
\hline & & & & & $\begin{array}{ll}\text { CT } & (\text { BCT+ } \\
\text { LCCA }) & \& \text { LSA }\end{array}$ & $\begin{array}{l}\text { BCT, LCCA, } \\
\text { LVA \& LSA }\end{array}$ & $\begin{array}{l}\text { Other } \\
\text { types }\end{array}$ \\
\hline $\begin{array}{l}\text { Nelson } \quad \text { and } \\
\text { Sparks, }{ }^{[9]}\end{array}$ & 2001 & Japanese & 94.3 & 5.7 & 1.1 & 4.1 & 0.5 \\
\hline $\begin{array}{l}\text { Nayak, Pai, } \\
\text { Prabhu et al. }\end{array}$ & 2006 & Indian & 90.4 & 9.6 & 4.8 & 1.6 & 3.2 \\
\hline $\begin{array}{l}\text { Suresh, Ovchin- } \\
\text { nikov and } \mathrm{Mc} \\
\text { Rae, }{ }^{[12]}\end{array}$ & 2006 & Trinidadian & 75 & 25 & 16.6 & 8.3 & 0.1 \\
\hline $\begin{array}{l}\text { Natsis, Tsi- } \\
\text { touridis, Didage- } \\
\text { los et al. }{ }^{[14]}\end{array}$ & 2009 & Greek & 83 & 17 & 15 & 1.7 & 0.3 \\
\hline $\begin{array}{l}\text { Haifa A. Alsaif } \\
\text { and Wafaa S. } \\
\text { Ramadan, }{ }^{[15]}\end{array}$ & 2010 & $\begin{array}{l}\text { Saudi Ara- } \\
\text { bia }\end{array}$ & 75 & 25 & 17 & 6 & 2 \\
\hline $\begin{array}{l}\text { Bhattarai and } \\
\text { Poudel, }{ }^{16]}\end{array}$ & 2010 & Nepalese & 80 & 20 & 11 & 7 & 3 \\
\hline Present study & 2014 & South Indian & 72 & 28 & 20 & 4 & 4 \\
\hline
\end{tabular}

embryological basis and review. J Vas Bras. 2006;5(2):95100. Available from: https://dx.doi.org/10.1590/s167754492006000200004.

12. Suresh R, Ovchinnikov N. Variations in the branching pattern of the aortic arch in three Trinidadians. West Indian Med J. 2006;55(5):351-353. Available from: https://www.researchgate.net/deref/http\%3A//dx.doi.org/ 10.1590/S0043-31442006000500012.

13. Ogeng'o JA, Olabu BO, Gatonga PM, Munguti JK. Branching pattern of aortic arch in a Kenyan population. J Morphol Sci. 2010;27(2):51-55.

14. Natsis KI, Tsitouridis IA, Didagelos MV, Fillipidis AA, Vlasis $\mathrm{KG}$, Tsikaras PD. Anatomical variations in the branches of the human aortic arch in 633 angiographies: clinical significance and literature review. Surg Radiol Anat. 2009;31(5):319-323. Available from: https://dx.doi.org/10.1007/s00276-008-04422.

15. Alsaif H, Ramadan W. An Anatomical Study of the Aortic Arch Variations. J King Saud Univ Sci. 2010;17(2):37-54. Available from: https://dx.doi.org/10.4197/med.17-2.4.

16. Bhattarai C, Poudel PP. Study on the variation of branching pattern of arch of aorta in Nepalese. Nepal Med Coll J. 2010;12(2):84-86.

Copyright: (C) the author(s), 2020. It is an open-access article distributed under the terms of the Creative Commons Attribution License (CC BY 4.0), which permits authors to retain ownership of the copyright for their content, and allow anyone to download, reuse, reprint, modify, distribute and/or copy the content as long as the original authors and source are cited.

How to cite this article: Naik SK, Premchand SA, Benjamin W. Anatomical Variations in Branching Pattern of Arch of Aorta A Cadaveric Study in South Indian Population. Acad. Anat. Int. 2020;6(2):69-72.

DOI: dx.doi.org/10.21276/aanat.2020.6.2.15

Source of Support: Nil, Conflict of Interest: None declared. 